\title{
A fotografia e seus duplos: um quadro na parede
}

\author{
Photography and its doubles: a picture on the wall
}

\author{
Mauricio Lissovsky \\ Professor do Programa de \\ Pós-graduação da Escola de \\ Comunicação/Universidade Federal \\ do Rio de Janeiro (UFRJ). \\ Avenida Pasteur, 250/Fundos/ \\ Palácio Universitário \\ 22290-240 - Rio de Janeiro - RJ - \\ Brasil \\ mauricio.lissovsky@eco.ufrj.br
}

\section{Juliana Martins}

Doutoranda do Programa de Pós-graduação da Escola de Comunicação/UFRJ.

Avenida Pasteur, 250/Fundos/ Palácio Universitário

22290-240 - Rio de Janeiro - RJ Brasil

jmes@uninet.com.br
LISSOVSKY, Mauricio; MARTINS, Juliana. A fotografia e seus duplos: um quadro na parede. História, Ciências, Saúde - Manguinhos. Rio de Janeiro, v.20, supl., nov. 2013, p.1363-1375.

\section{Resumo}

Hans Belting sugere que as 'imagens são os nômades dos meios', porque montam e desmontam acampamento a cada surgimento de uma nova mídia. Sempre que a fotografia retrata outra imagem (pintura, tela de tevê) encena um capítulo dessa história. A fotografia foi guardiã dos paradoxos da distância e das tensões entre imagem e mundo na modernidade. Por isso ocupa hoje lugar crucial no debate acerca da visualidade contemporânea. Nosso destino e o das imagens estão de algum modo entrelaçados. A última geração de artistas visuais do século XX procurou expressar a dor da virtualização; a fotografia do século XXI redescobre a promessa de corpo latente em cada imagem.

Palavras-chave: teoria da fotografia; fotografia contemporânea; imagem; corpo; história visual.

\section{Abstract}

Hans Belting suggests that 'images are the nomads of media' because they set up and dismantle their camps every time new media appear. Whenever photography portrays another image (painting, TV screen) it plays out a chapter in this history. Photography has been the guardian of the paradoxes in the distance and tensions between image and world in modern times. This is why it now holds a central position in the debate about contemporary visuality. Our fate and the fate of images are somehow interconnected. The last generation of visual artists from the twentieth century sought to express the pain of virtualization; twenty-first century photography is rediscovering the promise of a latent body in each image.

Keywords: theory of photography; contemporary photography; image; body; visual history. 
P or quais caminhos uma nova 'pequena história' da fotografia poderia nos levar - uma história que começasse a ser escrita de olho nas imagens que Walter Benjamin jamais viu? Quando o filósofo redigiu seu ensaio, em 1931, considerava que os primeiros cem anos da fotografia haviam sido marcados por debate teórico infrutífero, sob todos os aspectos, uma vez que comungavam os debatedores de um conceito de arte alheio a qualquer consideração técnica Ao longo de seus primeiros cem anos e apesar de seu desenvolvimento acelerado, a fotografia havia persistido em justificar-se "diante do mesmo tribunal que ela havia derrubado" o tribunal da arte (Benjamin, 1985, p.92). Bandeiras como a da 'arte pela arte' tentavam apenas proteger o gênio "contra o desenvolvimento da técnica" (Benjamin, 1970, p.135).

Frustrou-se a previsão de que o 'tribunal da arte' tinha seus dias contados, uma vez que subsistia graças a uma aura postiça, arrematada numa queima de estoque das religiões secularizadas. Desde a década de 1990, testemunhamos o ingresso da fotografia nos foros da arte. Em larga medida, a própria fotografia teve papel decisivo no que veio a chamar-se de arte pós-moderna, particularmente na constituição deste novo habitante dos museus e galerias que atende pelo nome de artista visual. No início dos anos 1990, o historiador e crítico André Rouillé (1998, p.304) já sugeria que "o devir-arte" da fotografia era "inseparável do declínio histórico de seus usos práticos", isto é, quanto mais "diminuía a eficácia da fotografia enquanto instrumento e poder" mais disponível para a arte ela se tornava. O crítico e curador francês Régis Durand (1995) concordava com o julgamento de que a artisticidade da fotografia era, em larga medida, um efeito colateral ou compensatório de deslocamentos no "campo das representações", no qual a fotografia perdera o lugar privilegiado que, durante algumas décadas, havia sido seu: "cada vez que um campo perde algumas de suas funções ou renuncia a elas, ele ganha autonomia artística" (p.19). ${ }^{1}$

De que lugar, porém, a fotografia havia sido deslocada? Em 1946, o crítico de The Nation Clement Greenberg (1986, p.60-61) afirmou, em sua resenha da exposição de Edward Weston no MoMA, de Nova York, que a "fotografia era o mais transparente dos meios artísticos", por isso seria "tão difícil fazer as fotografias transcender à sua função quase inevitável de documento e atuar como uma obra de arte enquanto tal". As duas funções, no entanto, não eram "incompatíveis". A fotografia seria a "única arte que ainda poderia bancar-se naturalista", alcançando "seu melhor efeito por meio do naturalismo". A única capaz de fazê-lo sem cair na "banalidade". Cerca de quarenta anos depois, o crítico de fotografia do New York Times Andy Grundberg (1999, p.231-232) observaria que a "era da reprodutibilidade técnica" tinha dado vez à "era da simulação eletrônica", e constatava que os artistas pós-modernos "estão interessados na fotografia não como um meio distinto para descrever o mundo, mas como uma encarnação ou metonímia de como a cultura se representa". No limite, é como se a fotografia se tivesse sacrificado (ou aquilo que imaginariamente fora) para que uma "arte pós-moderna" viesse a existir.

Essa seguramente não é a única história que os últimos cem anos (os nossos cem anos) podem contar. Há uma história interna ao dispositivo, por exemplo, em que a aceitação da técnica abre uma zona de resistência ao mecânico que faz da hesitação o núcleo da experiência de subjetivação do fotógrafo moderno. Essa é a história que se procurou contar em A máquina de esperar (Lissovsky, 2008). Mas há ainda outra, entre tantas possíveis, que diz respeito às relações entre imagem e mundo, uma história que, de tão comprida, quase se confunde com 
a da própria humanidade. Assim como não podemos beber água na palavra 'copo', como o esquizofrênico da anedota, também as imagens que formamos a partir do mundo vivem constantemente ameaçadas por aquelas que emergem da memória, do sonho, da imaginação, do transe, da possessão. Por isso, se seguimos Rosalind Krauss (1990, p.24), a fotografia contemporânea apenas exacerbou a vocação crítica que nela sempre esteve inscrita: "um projeto de desconstrução no qual a arte é distanciada e separada de si mesma".

De fato, desde sua invenção, a fotografia foi progressivamente ocupando o lugar - tão necessário quanto problemático - de guardiã da distância das imagens em um mundo desencantado. Um papel que desempenhou até finais do século passado, não como um leão de chácara, mas como uma bailarina equilibrada numa corda bamba esticada de uma ponta a outra de nossa consciência. Zelava por esta distância -, entre a imagem que certifica e a que ilude, entre a transparência e a opacidade do mundo - tensionando-a, pois não podia parar de percorrê-la, sob o risco de despencar. Uma 'política das imagens' da qual nos dava testemunho toda vez que colocava outro 'quadro' em cena: uma pintura, uma tela de cinema ou de televisão, outra fotografia.

Talvez fosse de olho nessa bailarina que Robert Frank, nos anos 1970 - quando praticamente já havia abandonado a fotografia em favor do cinema -, passa a pendurar em um varal, contra o horizonte da Nova Escócia, algumas de suas fotos clássicas. O historiador da arte alemão Hans Belting compreende que esse é um gesto de desapego em relação à unicidade do registro fotográfico, um esforço derradeiro para restabelecer seu lugar em um fluxo contínuo de lembranças. "Para mim, a imagem deixou de existir" (Belting, 2007, p.293) - diria Frank na época. Tratava-se de trabalhar a imagem no meio, mas contra o domínio do meio. Preservar a imagem desse meio - a fotografia - que agora insistia em convertê-la em coisa. Se o distanciamento pudesse estar ainda aí, "no âmago da coisa", registraria Blanchot (1987, p.257), já não seria "a mesma coisa distanciada mas essa coisa como distanciamento". Das palavras ditas (words) e das imagens vistas, porém, receava o artista, teriam sobrado apenas objetos.

De seu refúgio no litoral gelado do Canadá, Frank observava as grandes transformações no campo da imagem, suscitadas, em larga medida, pelo advento e difusão dos meios eletrônicos. Três fotos clássicas, comentadas a seguir, nos ajudam a compreender como a fotografia do século XX conduziu sua política das imagens até a cena contemporânea - testemunhos de uma pequena história das relações entre fotografia e outros modos de ser imagem.

\section{Na fila do pão}

Na edição de 15 de fevereiro de 1937, a revista Life estampou na página 9 uma das fotos mais famosas de Margaret Bourke-White: diante de um outdoor que mostra a família branca, sorridente, em viagem de férias em seu carro, uma fila de homens e mulheres negros, refugiados das enchentes em Louisville (naquele ano, as cheias dos rios Ohio e Mississipi haviam produzido quase um milhão de desabrigados) (Figura 1). O texto que lhe serve de legenda enuncia: "A inundação deixa suas vítimas na fila do pão". Na Life os fotógrafos eram as estrelas - a ponto de os repórteres estarem frequentemente encarregados de transportar malas e equipamentos dos colegas. Conta-se que, no caso de Bourke-White, o repórter tinha a obrigação adicional de lavar-lhe as roupas. A fotógrafa era conhecida pelas proezas e riscos 


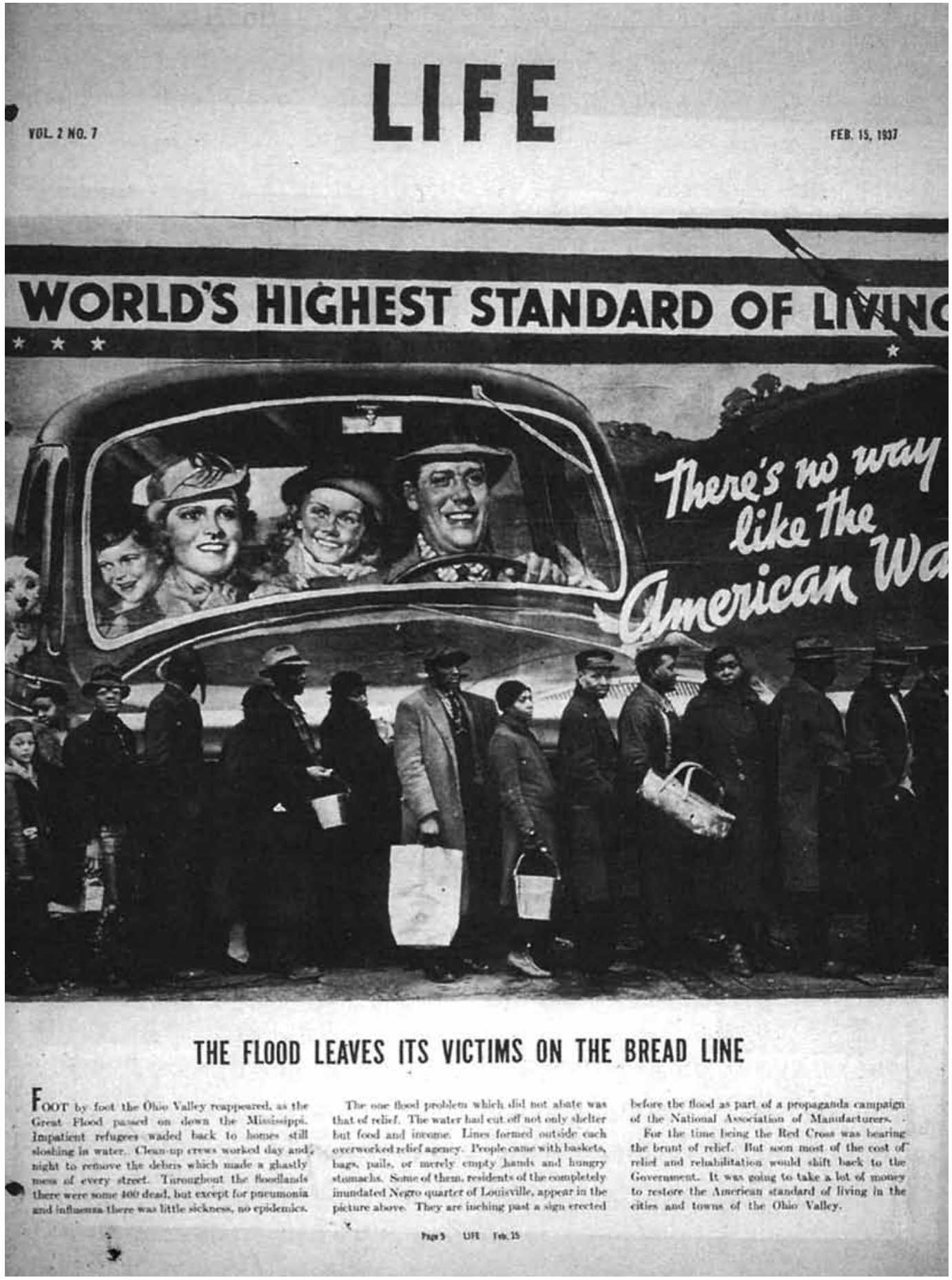

Figura 1: Revista Life, 15 fev. 1937 
a que se expunha e pelo modo como compunha cenas com a mesma firmeza com que um diretor de cinema comandaria o set de filmagem: trabalhava com vários flashes sincronizados; seus assistentes interrompiam o trânsito, se necessário; e ela não hesitava em orientar as pessoas sobre onde sentar-se ou para onde olhar. Tida como a mais famosa repórter fotográfica do mundo, Bourke-White rivalizava em fama com atrizes de Hollywood e posava como garotapropaganda de companhias aéreas, vinhos californianos, telefones e cigarros.

A fotografia da enchente em Louisville é de fácil leitura e grande impacto, exatamente as qualidades que Bourke-White procurava reunir em suas imagens. A ironia do contraste entre a família branca motorizada e os negros desabrigados é acentuada pelos dizeres do outdoor: uma faixa adornada com estrelas proclama que os Estados Unidos têm o 'mais alto padrão de vida do mundo'; e uma anotação em letra cursiva provém diretamente da experiência da família, atestando que 'There's no way like the American Way'. Esse jogo de contrastes, porém, não esgota a força dessa fotografia: no momento em que o carro do outdoor é capturado pelo flagrante fotográfico, o veículo ganha velocidade. E com o auxílio da teleobjetiva acoplada à câmera Linhof, Bourke-White nos mostra que o acidente é iminente, que os pedestres na fila do pão serão atropelados, e que desse terrível desastre talvez escape apenas o cachorrinho. A inundação de Louisville, tal fotografia nos sugere, é apenas mais uma entre tantas mazelas pelas quais passam os negros da América.

Bourke-White não entendia que as justaposições irônicas de suas imagens resultassem de alguma habilidade construtiva particular. As ironias já estavam presentes no mundo, sustentava, como uma espécie de retórica espontânea (Tagg, 2009, p.112-113) Os outdoors There's no way... estavam espalhados pelas estradas e eram parte de uma campanha publicitária promovida pela maior entidade patronal da indústria norte-americana, a National Association of Manufacturers (NAM). Seu objetivo, segundo o historiador da fotografia John Tagg (2009), era angariar apoio junto ao 'público' contra as leis de proteção ao trabalho - que vinham sendo progressivamente propostas e implantadas no âmbito do New Deal - e as greves de trabalhadores organizadas pela American Federation of Labor. Afinal, segundo o slogan de uma campanha patronal anterior: "a prosperidade mora onde reina a harmonia" (p.120).

Neste momento nos damos conta de que a intrincada superposição de imagens e textos dessa fotografia não se esgota na crítica social. A foto de Bourke-White não visa apenas apreender um real que se apresenta como tal, mas encenar seu confronto com o imaginário, representado pelas personagens do cartaz. Em contraste com o outdoor, que se revela então um ridículo mercador de ilusões, a fotografia recobra algo do mundo tridimensional de onde proveio. A eficácia do cartaz fragiliza-se diante do mero confronto com a realidade. No acurado comentário de John Tagg (2009, p.113):

O cartaz não é nada além de uma representação, claramente inadequada diante da realidade da 'fila do pão'. Essa é a má-fé da representação: a representação é tendenciosa, motivada, enganosa. ... Nós vemos a verdade agora. A cuidadosa construção retórica da imagem nos trouxe até este ponto. A representação, que parecia estar sendo colocada em questão nessa fotografia, está sendo apenas citada, aspeada na imagem: o que permanece fora de quaisquer aspas é o próprio real.

Nessa página histórica, Bourke-White e a Life celebram a superioridade moral da fotografia sobre a ilustração. Depois de décadas padecendo seu complexo de inferioridade diante da 
pintura, a fotografia documental esfregava a transparência de seu tacão realista sobre os restos insepultos do 'pictorialismo'.

\section{À beira do caminho}

Em finais da década de 1930, o documentarismo já começara a construir seu cânone, e as revistas ilustradas transformavam fotógrafos em heróis populares. Segura de si mesma, a fotografia empurrava a ilustração pictórica para o fundo da cena. Como a tela de um teatro mambembe, servia agora apenas de contraste para a performance dos verdadeiros atores. Pouco mais de uma década depois - década, porém, que valeu por meio século, pois abriga a catástrofe da Segunda Grande Guerra - André Kertész realiza outra de suas naturezas-mortas (Natureza-morta, 1951). A foto não busca aqui o contraste com a pintura, antes lhe toma um de seus motivos mais característicos. A própria materialidade da pintura comparece, adornando a parede que serve de fundo à fruteira em primeiro plano.

A intenção de Kertész não é opor fotografia e pintura - tal como havia feito Bourke-White-, mas estabelecer entre ambas um estranho jogo de reciprocidades e intercâmbios. Quem buscasse interpretar essa imagem a partir dos procedimentos retóricos utilizados pela estrela da Life poderia ver ali a fotografia 'desenquadrando' a pintura. Ou, inversamente, o fracasso da fotografia que, a despeito de produzir belas obras, permaneceria atavicamente presa ao mundo real 'fora da moldura', sendo, por esse motivo, discriminada e subestimada no campo das artes.

Tudo isso, porém, é insuficiente. A trama de sentidos montada por Kertész é ainda mais complexa do que a de Bourke-White. Essa singela natureza-morta faz parte do livro On reading (Sobre a leitura), reunião de fotos de pessoas lendo que o fotógrafo realizara ao longo de muitas décadas. Sim, há alguém lendo nessa imagem, mas não foi o dispositivo fotográfico que a surpreendeu nessa situação, mas a própria pintura. Sentada à sombra de uma árvore, uma donzela se deixa 'flagrar' absorta na leitura. Enquanto, no caso do atropelamento da fila do pão, as temporalidades da ilustração e da fotografia convergem para um único instante, na foto de Kertész elas se confundem: a eternidade da natureza-morta agora habita a fotografia, enquanto a pintura absorve as qualidades do instantâneo que interrompe o curso de uma ação. E, como para tornar esse contrabando de temporalidades ainda mais 'complicado', pode-se suspeitar que as frutas da natureza-morta também estejam presentes no cesto que a jovem leitora tem a seu lado. Teriam sido recém-colhidas pela moça, que agora descansa? Ou ela as levou consigo para prolongar mais seu passeio?

Por quanto tempo essa condição de fraterno intercâmbio entre fotografia e pintura, que essa imagem encena, irá perdurar? Terá de fato existido algum dia? Ou testemunhamos aqui apenas o desejo de um fotógrafo que desde sua emigração para os Estados Unidos, em 1936, só recebia encomendas de revistas de segunda linha? Quando compôs essa natureza-morta, Kertész estava há cinco anos sem expor uma fotografia sequer e ainda teria que amargar mais 11 anos de ostracismo (Steichen deixou-o fora de The family of man). Nunca conseguiu dominar o inglês e certa vez um editor criticou suas imagens por "falarem demais" (Dyer, 2007, p.27-28). Em contraste com a enchente de Louisville, contudo, Natureza-morta, 1951, é peculiarmente silenciosa. A fotografia de Bourke-White está repleta de palavras que aviltam ainda mais a situação por que passam as vítimas das inundações. A de Kertész, a despeito de 
tematizar a leitura, mantém ocultas as palavras, transformando a fotografia em oportunidade de mergulharmos na experiência de interioridade à qual a literatura costuma estar associada.

No mundo Life de Bourke-White, as imagens talvez fossem capazes de dizer tudo. As palavras se tornariam ociosas ou transformar-se-iam elas próprias também em imagens, como sucede aos dizeres do outdoor. Tal qual Proust (1991, p.10), porém, Kertész prefere debruçarse sobre os "livros de outrora". Escolheu voltar a folheá-los como calendários dos "dias perdidos", na esperança de ver refletidas em suas páginas "as habitações e os lagos que não existem mais", pois o que "as leituras da infância deixam em nós é a imagem dos lugares e dos dias em que as fizemos" (p.24).

\section{Em todos os lares da América}

Enquanto Kertèsz refugia-se na leitura, um novo estado da imagem penetra, tão avassaladoramente quanto uma enchente do rio Ohio, todos os lares da América: a televisão. As transformações profundas que engendra já não estão mais confinadas ao campo da imagem, mas dizem respeito aos próprios corpos dos espectadores. É isso que Garry Winogrand testemunhou em seu flagrante de John Kennedy, candidato a presidente, discursando na Convenção Nacional do Partido Democrata, em 1960.

Aqui, a aura de luz em torno do político confunde-se com a luz que o banha para que ele próprio tenha seu corpo transformado em ondas eletromagnéticas televisivas. Fotografar o discurso do futuro presidente é também silenciar sua fala em prol de sua imagem. É uma fotografia duplamente profética. Premonitória a respeito de uma campanha que, segundo os cientistas políticos, foi a primeira em que venceu o carisma midiático de um jovem Kennedy contra seu rival, Richard Nixon, então um representante da velha escola (vitimado mais pela sudorese do que pela retórica); mas também premonitória do que viria a tornar-se um clichê acadêmico nas décadas seguintes: a fotografia, o cinema e a televisão estavam em vias de transformar o mundo e nós todos em imagem. Daniel J. Boorstin, importante historiador e intelectual norte-americano, que seria por muitos anos diretor da Biblioteca do Congresso, queixava-se, em 1962 (em um livro chamado A imagem: um guia para pseudoeventos na América), de que as imagens se haviam misturado ao 'sonho americano': "nós nos apaixonamos por nossa própria imagem, pelas imagens que criamos, que acabaram por tornar-se imagens de nós mesmos". E concluía: "como indivíduo e como nação, nós agora sofremos de narcisismo social" (citado em Stimson, 2006, p.1-2).

Ao flagrar, nos fundos da cena, a transformação do político em imagem midiática (os novos 'dois corpos do Rei'), a fotografia ainda preserva algo de seu estatuto testemunhal. Ela ainda diz algo do mundo, sem (supostamente) dizer de si mesma: revela os bastidores de uma ação invisível para quem está presente à convenção e admira a performance do políticocorpo; e desvela, apenas para os espectadores da fotografia, a nova face do político-imagem.

\section{No jardim das ninfeias}

O fim da era moderna e o início do que alguns chamariam de pós-moderno, que essa fotografia de Winogrand prenuncia, assinalam aqui esse gozo narcísico generalizado no 
qual mergulhamos e que perdura até hoje. Não admira que, nessas circunstâncias, a própria imagem possa assumir caráter monumental. Todos nos tornamos um pouco turistas, com o olhar colonizado por imagens já vistas, viajando para ver o que já se conhece. Isso é o que demonstra, de forma bem-humorada, o vídeo Steps (1987), de Zbig Rybczynski, em que um grupo de turistas visita a locação do filme soviético Encouraçado Potemkin, dirigido por Serguei Eisenstein, em 1925, dispondo até de guia cuja missão é explicar-lhes a poética do filme. Na cena da escadaria de Odessa, os turistas misturam-se à multidão e são igualmente, alvejados, postos para correr e pisoteados pelo Exército tsarista.

A nova monumentalidade da imagem não é apenas um artifício retórico - a hipérbole de seus atributos ontológicos. Ao longo de muitas décadas, a função de mediadora das relações entre imagem e mundo encontrou no livro o lugar privilegiado de sua realização. Feita para a página impressa, a fotografia cabia em nossas mãos (propriedade de 'miniaturização' que Walter Benjamin celebrou); a fotografia monumental, agora destinada às paredes das galerias de arte, onde "ela importa como arte como nunca antes" (Fried, 2008), desloca o lugar do observador. Na fotografia moderna, a inteligibilidade e a fruição da imagem demandavam do espectador a mobilização imaginária do olhar testemunhal de quem poderia ter estado lá. A contrapartida fenomenológica do 'isto foi' barthesiano era o 'poderia ter sido eu acionando o obturador'.

A confluência dessas duas intuições - a rigor, paradoxais - constituiu o âmago da experiência fotográfica do século XX. Antes de ser causa das transformações no campo do observador, a monumentalidade das fotografias contemporâneas deve ser tomada como seu índice ou sintoma. A liberdade de movimentos do espectador diante da imagem, exaltada por Fried, tem como contrapartida a diluição desse lugar privilegiado em que ponto de vista espacial e aspecto temporal imiscuem-se um no outro. Não resta dúvida de que a fotografia cumpriu papel crucial na transformação do mundo em imagem, alterando o modo como o habitamos; mas algo também sucedeu conosco. Na obra de Roberta Dabdab, que Éder Chiodetto incluiu na exposição Geração 00, tudo está sabido de antemão: conhecemos tanto a situação de fotografar quanto a de ser fotografado ao lado de monumentos, pois não é outro o sentido dessa pintura de Monet nas paredes do Museu de L'Orangerie: um monumento que conhecemos ou teríamos que conhecer (Figura 2).

A fotografia apropria-se tanto da plasticidade impressionista - em que o corpo do observador estava implicado na apreensão de uma obra que não se resolvia em si mesma - quanto da situação museográfica que induz uma absorção do visitante na obra (algo que já havia sido tematizado por Thomas Struth). Na fotografia de Roberta Dabdab não são apenas os limites entre pintura, fotografia e corpo que desaparecem. Também não se trata mais de alertar sobre o risco de preferirmos nossa imagem em detrimento de nós mesmos - como foi feito ao longo das décadas de 1960 e 1970. A pixelização generalizada sugere agora que o verdadeiro risco (fato talvez já consumado) é o desaparecimento das distinções entre imagem e mundo (ou, antes, do problema dessas distinções). Quando a artista escreve na legenda "Mulher fotografa homem em frente às gigantescas ninfeias..." isso remete menos a um fragmento de mundo do que à revelação de que mundo, imagem, e essa mulher que fotografa (a própria artista, afinal) já habitariam um cenário em que não apenas as distinções quanto aos regimes de representação se evanesceram, mas do qual desapareceram também todas as diferenças materiais. 


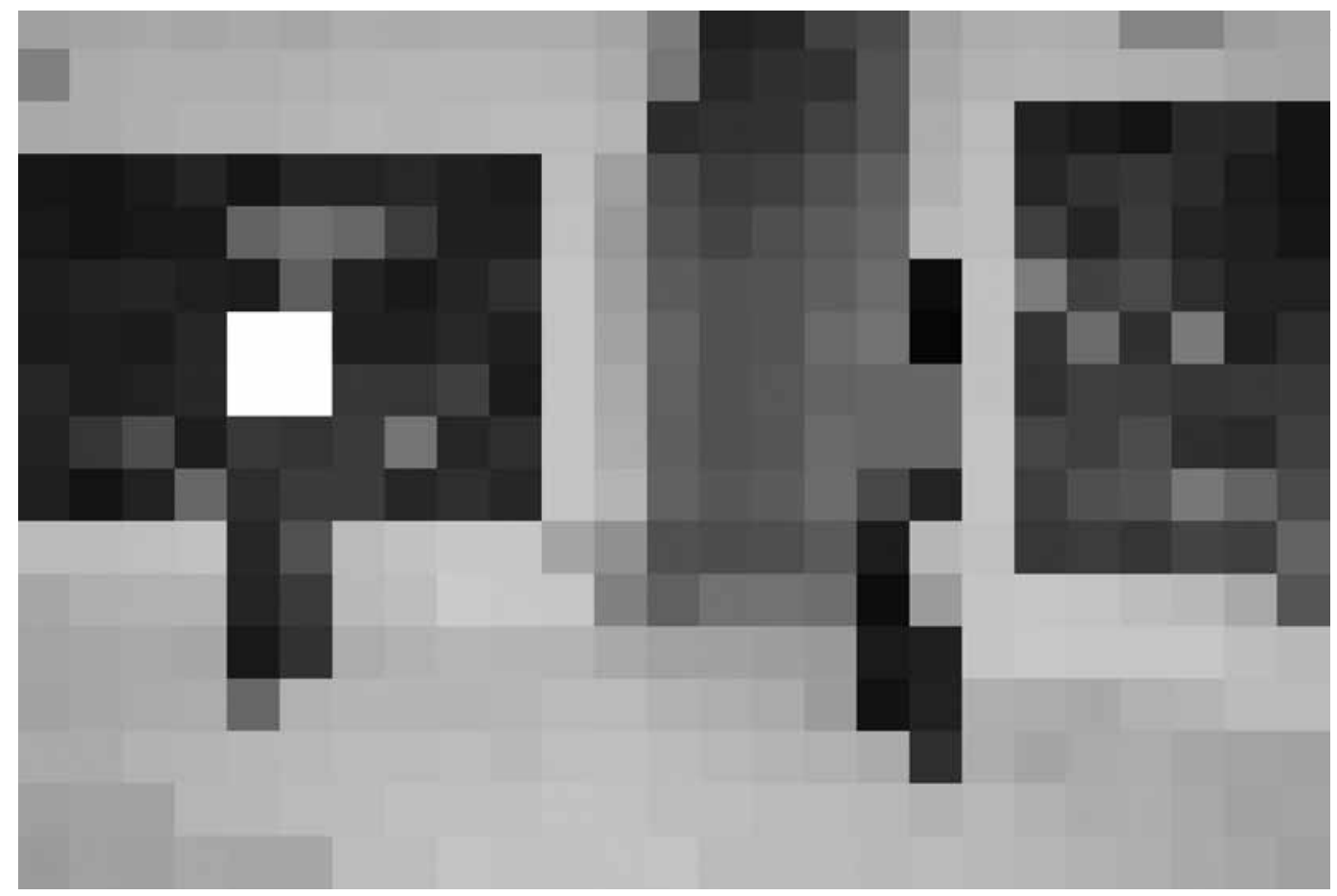

Figura 2: Roberta Dabdab, Mulher fotografa homem, em frente às gigantescas ninfeias de Monet, no Museu L'Orangerie, 2008

Parece-nos, hoje, que a tensão fundamental constitutiva da fotografia e de sua cultura não foi entre verdade e mentira ou entre arte e técnica (para mencionar apenas os debates clássicos), mas entre imagem e mundo. Deslocada pouco a pouco do lugar, que ocupou durante mais de 150 anos, de guardiã problemática dessa distância-diferença, o experimentalismo e o hibridismo contemporâneos não refletem apenas as mudanças radicais por que passa uma determinada prática cultural. São igualmente alimentados pela intuição de que nosso destino e o destino da fotografia estão, de alguma maneira, vinculados.

\section{Fotografia e corpo: destinos entrelaçados}

A fotografia ocupa hoje lugar crucial na reflexão acerca da visualidade contemporânea. Do famoso debate entre o filósofo francês Jacques Rancière e o iconólogo norte-americano J. T. W. Mitchell, na Universidade de Columbia, em 2008, depreende-se, que nosso destino e o destino da fotografia estão de algum modo entrelaçados. Naquela ocasião, Rancière chamava a atenção para dois discursos contemporâneos acerca da imagem, ambos catastróficos. Um deles afirmava que não há mais nada de real no mundo, que tudo se tornou virtual, um desfile de simulacros e imagens sem qualquer substância. O outro sustentaria que são as próprias imagens que acabaram, uma vez que a imagem supõe certa distância da realidade, distância que nos permite operar as distinções entre uma coisa e outra. Se já não podemos realizar essa operação, então a imagem, como categoria do pensamento, não existiria mais. Para Rancière (2009, p.21-22), o que está por trás desses discursos é a lamentação pela 'morte' das imagens passadas, tanto do ponto de vista material quanto simbólico, degradadas e vulgarizadas pela sociedade de consumo de massa. Nesse sentido, não é por acaso que a cena da pixelização generalizada, flagrada por Dabdad ocorra em um museu, instituição que se converteu na 
modernidade em "refúgio para imagens que haviam perdido seu lugar no mundo" (Belting, 2007, p.77). Nossa ansiedade em relação às imagens, porém, não decorreria apenas das transformações de natureza civilizacional que atravessamos. Mitchell (2009) irá argumentar que, tal como os animais - aos quais estão ligadas desde tempo paleontológicos -, as imagens nos predizem e precedem.

A ansiedade marcou a última geração de artistas visuais do século XX, que viveu na pele a própria virtualização, tomando para si a tarefa de inscrever na fotografia as dores de parto da nova imagem. Nesse sentido, a obra de Rosângela Rennó (2010) é exemplar. Em um magnífico livro, fotografias roubadas da Biblioteca Nacional e depois recuperadas pela polícia, exibem apenas o verso; e nele as marcas de sua desventura: inscrições, carimbos, etiquetas, raspagens, apagamentos.

No entanto, nem o mundo nem a imagem desapareceram, ainda que suas relações se estejam reconfigurando. A primeira geração de fotógrafos brasileiros do século XXI começa a desfrutar do esquecimento do corpo das imagens. De fato, as fotografias sacrificaram seu corpo para que produção e reprodução não fossem mais operações materialmente distintas. Nas comunidades de imagens virtuais da internet, as fotografias estão agora tomadas por um "delírio de onipotência, uma fantasia que encontrou na replicação infinita a justificativa autorreferente de sua existência". Na rede que lhes serve de habitat natural e caldo de cultura, as imagens-clichê "querem nos fazer crer que agora, mais do que nunca, a reprodução é parte indissociável da sua natureza" (Lissovsky, 2012, p.25), uma vez que sua mera exibição na tela de vídeo de um computador já é reprodução em ato.

O esquecimento do corpo das imagens fotográficas, no entanto, tal como se deu com o esquecimento da duração por ocasião do advento da fotografia instantânea moderna, faz sintoma. E o que toma a cena, por vezes, é a promessa de corpo que sempre esteve latente em toda imagem. Promessa de que nos falam as religiões da encarnação, em particular o cristianismo. Promessa que a condição moderna da imagem havia obscurecido em nome da elaboração da própria transparência e que teve sua contrapartida nas teorias semióticas e hermenêuticas em que um mundo de signos era abstraído do mundo dos corpos (Belting, 2007, p.18-19).

O encontro paradoxal entre os deuses antropomórficos greco-romanos com o deus único e incorpóreo da tradição judaica resultou no ícone cristão em que a "desencarnação se converteu no sentido da nova imagem do corpo" (Belting, 2007, p.119). Essa imagemdesencarnada-promessa-de-corpo tem seu apogeu nos ritos fúnebres dos reis medievais, descritos por Kantorowicz (1989, p.30-38), em que a dignidade do cargo, a imagem da soberania, busca um novo corpo para recompor a integridade do reino e da autoridade real. Essa promessa ressurge agora no contexto de uma tecnologia em que informação e suporte tornaram-se autônomos uma em relação ao outro. A velha efígie dos reis parece ter-se transformado nos avatares que agem na 'extensão' virtual de nós mesmos, como se fossem corpos tornados imagem a "invalidar a diferença entre uma imagem e tudo aquilo do qual é imagem" (Belting, 2007, p.136). Agora percebemos que ao esquecimento do corpo das fotografias corresponde o esvanecimento do problema da distância entre e imagem e mundo.

Blanchot (1987, p.262) escreveu que existem duas modalidades de distância: a distância que tomamos das coisas para "melhor dispor delas" e a distância que é "profundidade não 
viva, indisponível, que se torna como que a potência soberana e derradeira das coisas". Um "utensílio danificado torna-se a sua imagem" - observa ele - "não mais desaparecendo no seu uso, 'aparece'". E acrescenta: "Essa aparência do objeto é a da semelhança e do reflexo: se se preferir, seu duplo", seu cadáver (p.260). Mas o que nos sugere a experiência contrária? A experiência dos duplos úteis e disponíveis, a experiência da sobreposição das duas modalidades de distância, do desabamento de uma sobre a outra? Por mais de um século, a fotografia foi este Atlas que suportava um céu de imagens com os pés firmemente cravados na terra das coisas. Não conheço melhor figura dessa condição do que a criada pelo caricaturista e cineasta francês Carlo Rim (1989, p.37-38), em 1930, quando afirmava que graças à fotografia o ontem se havia transformado em um "hoje sem fim": "Como o cabo que prende o balão à terra, nosso sensível aparelho permite-nos sondar o terreno mais difícil, criando um tipo de vertigem particularmente seu". Agora, desatadas, incorpóreas, como valquírias digitais, recolhem os restos mortais desse fenomenal desmoronamento. No lusco-fusco destes restos, a imagem desencarnada, vê-se o "reflexo tornando-se senhor da vida refletida": vêse o cadáver que "é sua própria imagem" (Blanchot, 1987, p.260). Durante todo o século XIX, a fotografia foi uma poderosa aliada da agenda iluminista de anexação do invisível aos territórios da visibilidade. Uma agenda que pautou a ciência do século XVII ao XIX em sua luta incansável contra a obscuridade do mundo, cujo marco inicial foi a invenção do microscópio, culminando no registro das sombras produzidas pelos raios $\mathrm{X}$ emitidos por um 'tubo de Crookes', em 1895. Sobre a primeira dessas radiografias, o inventor Wilhelm Röntgen anotou "fotografia de uma mão viva" (Figura 3). A fotografia não transpunha assim apenas os limites da carne, mas os próprios umbrais da morte. Nunca cessamos de nos admirar de que um dos dedos da modelo - a própria esposa do cientista, Anna Bertha -, se encontre adornado por um anel, signo da vaidade dos vivos e da fidelidade eterna dos casais. Ao contemplála pela primeira vez, dizem, a senhora Röntgen exclamou: "eu vi a minha morte!".

Em sua crítica ao apego que a ciência moderna nutria pelas profundidades em detrimento das superfícies, a 'falácia' de que as causas são mais importantes que os efeitos, ou, de um ponto de vista filosófico, a crença na supremacia do "Ser (verdadeiro) sobre a (mera) Aparência", Hanna Arendt (1978, p.26-30) Figura 3: Wilhem K. Röntgen, A mão da senhora Röntgen, 1895 
formas exteriores são "infinitamente variadas e altamente diferenciadas". Os "órgãos internos, por sua vez, a menos que deformados por uma doença ou anormalidade peculiar", são difíceis de distinguir um do outro: se o interior fosse visível, "nós todos pareceríamos iguais". E acrescenta: "qualquer coisa que veja deseja ser vista, qualquer coisa que ouça clama por ser ouvida, qualquer coisa que toque mostra-se para ser tocada". Tudo que é vivo, portanto, "urge aparecer", mas nossos "preconceitos metafísicos" nos teriam levado a acreditar que o essencial repousa sob a superfície, isto é, que "a superfície é 'superficial"”.

Se todo corpo morto é o vivo reduzido à sua imagem, sua contrapartida é que toda imagem é vida morta em busca de um corpo. E é desde as entranhas indiferenciadas da nova imagem que o desejo de corpo que as habita encontra sua expressão mais pungente. Expressão que não é mais, como assinalava Hanna Arendt (1978, p.30), a da interioridade "de uma ideia, de um pensamento, de uma emoção", mas "expressividade de uma aparência", que não exprime nada a não ser a si mesma. Em Retrato íntimo, de Cris Bierrenbach (Figuras 4 e 5), a dor torna-se um imperativo da própria imagem. Enquanto na 'fotografia esvaziada' de Dabdab, a substância imaterial do digital dissolve as distinções que só as palavras da legenda insistem em preservar, nesses retratos, matéria e imagem estão em tensão permanente. Tensão de que agora nenhuma palavra pode dar conta.

A tesoura e a seringa não cessam de convocar a carne da imagem e, simultaneamente, frustrar sua encarnação. Já não é preciso dizer, como o doutor Röntgen, que se trata da "mão

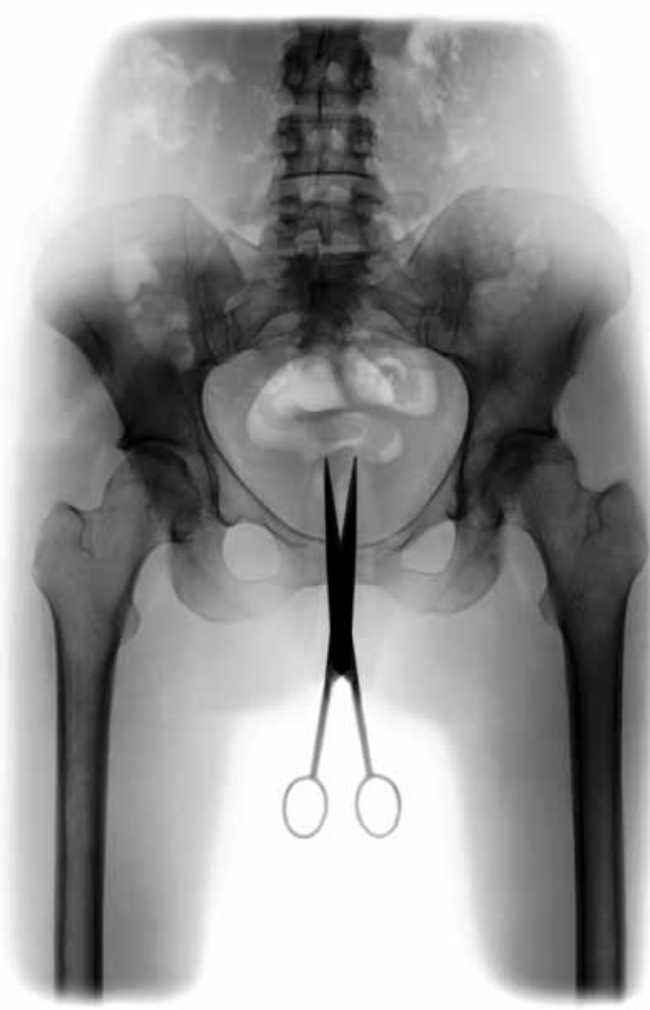

Figura 4: Cris Bierrenbach, Tesoura, da série Retrato íntimo, 2003

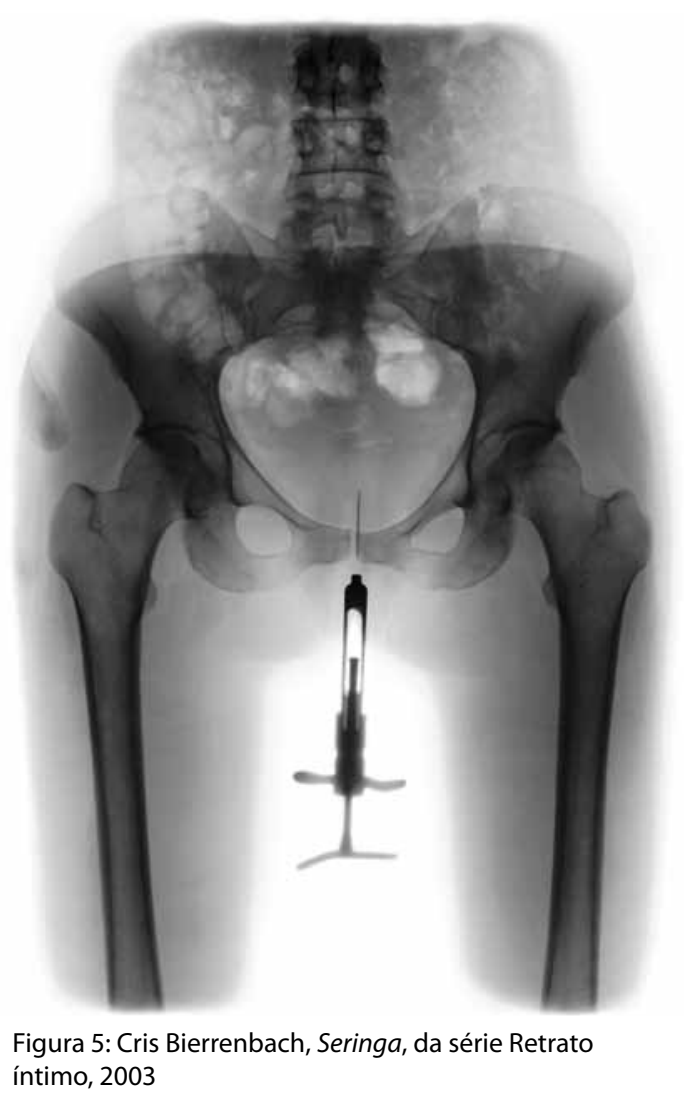

íntimo, 2003 
viva" de sua esposa, cuja devoção um anel testemunha. Ossos vivos já nos são familiares e o metal não mais os envolve, como um pequeno círculo protetor: o metal instiga, perfura. Dessa nova condição das relações das imagens entre si (e da fotografia com o mundo), Roberta Dabdab fez a anamenese, e Cris Bierrenbach, o relatório de autópsia: esgotada de tanto dizer, esvaziada de sua magia, a fotografia despojada de palavras reencontra no grito lancinante o único modo de dar voz ao real que subsiste nas entranhas da realidade. Por intermédio desse grito, o corpo retorna como a Terra Prometida das imagens.

\section{NOTA}

${ }^{1}$ Nessa e nas demais citações em língua estrangeira, a tradução é livre.

\section{REFERÊNCIAS}

ARENDT, Hanna.

The life of the mind. New York: Harvest/Harcourt. 1978.

BELTING, Hans.

Antropologia de la imagen. Madrid: Katz Editores. 2007.

BENJAMIN, Walter.

Pequena história da fotografia. In: Benjamin, Walter. Magia e técnica, arte e política. São Paulo: Brasiliense. p.91-107. 1985.

BENJAMIN, Walter.

Paris, capital del siglo XIX. In: Benjamin, Walter. Sobre el programa de la filosofía futura y otros ensayos. Caracas: Monte Avila. p.125-138. 1970.

BLANCHOT, Maurice.

O espaço literário. Rio de Janeiro: Rocco. 1987.

DURAND, Régis.

Le temps de l'image. Paris: La Différence. 1995.

DYER, Geoff.

The ongoing moment. London: Abacus. 2007.

FRIED, Michael.

Why photography matters as art as never before. New Haven: Yale University Press. 2008.

GREENBERG, Clement.

The collected essays and criticism. v.2. Chicago: University of Chicago Press. 1986.

GRUNDBERG, Andy.

Crisis of the real. New Jersey: Aperture. 1999.

KANTOROWICZ, Ernst.

Les deux corps du roi. Paris: Gallimard. 1989.

KRAUSS, Rosalind.

A note on photography and the simulacral. In: Squiers, Carol (Org.). The critical image. Seattle: Bay Press. p.15-27. 1990.
LISSOVSKY, Mauricio.

Os fotógrafos do futuro e o futuro da fotografia. In: Montaño, Sonia et al. (Org.). Impacto das novas mídias no estatuto da imagem. Porto Alegre: Sulina. p.13-27. 2012.

LISSOVSKY, Mauricio.

A máquina de esperar. Rio de Janeiro: Mauad X. 2008.

MITCHELL, William John Thomas.

The future of the image: Rancière's road not taken. Culture, Theory and Critique, London, v.50, n.2-3, p.133-144. 2009.

PROUST, Marcel.

Sobre a leitura. Campinas: Pontes. 1991.

RANCIÈRE, Jacques.

The future of the image. London: Verso. 2009.

RENNÓ, Rosângela.

2005-510117385-5. Rio de Janeiro: R. Rennó. 2010.

RIM, Carlo.

On the snapshot. In: Philips, Cristopher (Org.).

Photography in the Modern Era. New York:

Metropolitan Museum of Art; Aperture. p.37-40. 1989.

ROUILLÉ, André.

Da arte dos fotógrafos à fotografia dos artistas.

Revista do Patrimônio Artístico e Cultural, Rio de Janeiro, n.27, p.302-311. 1998.

STIMSON, Blake.

The pivot of the world: photography and its nation. Cambridge: MIT Press. 2006.

TAGG, John.

The disciplinary frame. Minneapolis: University of Minnesota Press. 2009. 


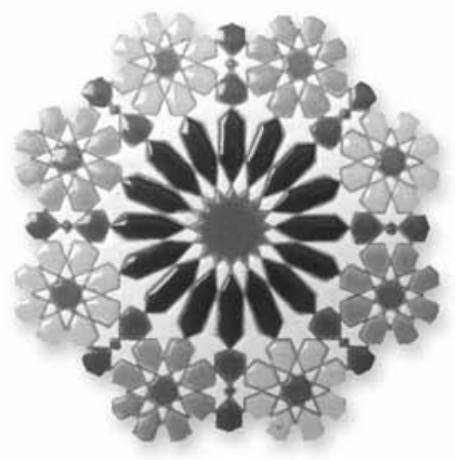

